\title{
Extension of reproductive suppression by pheromonal cues in subordinate female marmoset monkeys, Callithrix jacchus
}

\author{
J. Barrett, D. H. Abbott and L. M. George \\ $M R C / A F R C$ Comparative Physiology Research Group, Institute of Zoology, Zoological Society of \\ London, Regent's Park, London NW1 4RY,UK
}

\begin{abstract}
Summary. Pheromonal signals from the dominant female marmoset monkey were implicated in maintaining the suppression of LH secretion and ovulation in socially subordinate females. When subordinate, and reproductively suppressed, female marmoset monkeys were removed from their group without scent contact with their dominant females, subordinate females in control group $1(\mathrm{~N}=8)$ and control group 2 $(\mathrm{N}=5)$, ovulated $10.8 \pm 1.4$ days and $10.4 \pm 0.8$ days respectively (mean \pm s.e.m.) after separation. Subordinate females $(\mathrm{N}=8)$ removed from their dominant female and group, but maintained in scent contact only with their dominant females, showed a delay in the onset of ovulation $(31.0 \pm 6.4$ days) compared with control groups 1 and 2 . Plasma $\mathrm{LH}$ concentrations of subordinate females during the scent transfer phase were lower than in controls without scent transfer and comparable to those seen whilst the females were subordinates in groups. Contact of subordinate females with olfactory stimuli from dominant females therefore maintains the suppression of both $\mathrm{LH}$ secretion and ovulation in socially subordinate female marmosets. Such pheromonal cues provide evidence of a quantifiable link between dominant female marmosets and the maintenance of physiological suppression of reproduction in their female subordinates.
\end{abstract}

Keywords: marmoset; reproductive suppression; pheromones; ovulation; progesterone

\section{Introduction}

Marmoset monkeys establish social groups in the wild, amongst which only one female breeds (Stevenson, 1978; Hubrecht, 1984; Stevenson \& Rylands, 1988). Captive group-housed female marmoset monkeys establish a social hierarchy in which only the dominant or rank 1 female ovulates and breeds (Abbott \& Hearn, 1978; Abbott et al., 1981). Her subordinate females (ranks 2 and below) remain anovulatory as reflected by their low and acyclic concentrations of plasma luteinizing hormone ( $\mathrm{LH}:<2$ i.u./1) and plasma progesterone $(<10 \mathrm{ng} / \mathrm{ml}$ ) (Abbott et al., 1981, 1988). The suppressed pituitary LH secretion in subordinate females is accompanied by a diminished response of the pituitary to single injections of gonadotrophin-releasing hormone (GnRH; Abbott et al., 1988). Subcutaneous pulsatile infusions of GnRH given to subordinate females resulted in an increase in plasma $\mathbf{L H}$ concentrations comparable to those seen in normal ovulatory cycles (Ruiz de Elvira \& Abbott, 1986; Abbott, 1987, 1989). After infusion, plasma LH values returned to the low levels characteristic of subordinate females. These results therefore suggested that a hypothalamic block to $\mathrm{GnRH}$ is imposed upon the subordinate female by the dominant female.

Subordinate females do not suffer a permanent block to reproduction as removal from their social groups, and the influence of their dominant female, prompts a release of plasma $\mathrm{LH}$ and the 
onset of ovulation (Abbott et al., 1988). On re-introduction to a social group and a return to subordinate status there is a rapid decrease in plasma concentrations of $\mathrm{LH}$ and progesterone and a resumption of an anovulatory state.

In the closely-related tamarin species, Saguinus fuscicollis and $S$. oedipus, pheromonal signals from dominant females have been implicated in the suppression of ovulation in subordinate females. Young subordinate females maintained with their family groups had low, acyclic concentrations of urinary oestrogen indicative of suppressed ovarian function (Epple \& Katz, 1984; French et al., 1984). On removal from their natal groups for pairing with adult males urinary oestrogen concentrations rose in these subordinate females and ovarian cycles commenced. If, however, scent-marked plates or perches were transferred from the natal cage to that of the malefemale pairs, the paired females either exhibited elevated urinary oestrogen concentrations without any clear onset of ovarian cyclicity (S.fuscicollis: Epple \& Katz, 1984; $N=1$ ) or there was a delay in the onset of ovulation compared to subordinate females receiving uncontaminated perches ( $S$. oedipus: Savage et al., 1988; $\mathrm{N}=3$ ).

Marmosets, like tamarins, show an extensive scent marking repertoire (Stevenson \& Poole, 1976) and have well-developed circumgenital scent glands (Sutcliffe \& Poole, 1978). The aim of this study was to determine whether olfactory cues from dominant females provide an important sensory input imposing suppression of ovulation in their female subordinates.

\section{Materials and Methods}

\section{Animals and social group formation}

The marmoset monkeys were captive-born animals raised in the Institute of Zoology under the conditions described by Hearn (1983) with a constant photoperiod of $12 \mathrm{~h}$ light: $12 \mathrm{~h}$ dark. The 16 social groups were formed from unrelated marmoset monkeys, which were either offspring from family groups or from male female pairs. All animals used were post-pubertal (over 15 months of age), as previously described by Abbott et al. (1988).

To form a group, 2-4 males and 2-4 females were placed together in either (1) an observation room $(2.9 \times 2.2 \times 1.7 \mathrm{~m})$ fitted with interwoven tree branches and a nest box at $\mathrm{I} .2 \mathrm{~m}$ above floor level, or (2) a home cage $(100 \times 50 \times 75 \mathrm{~cm})$ with an exercise cage $(2 \times 1 \times 2 \mathrm{~m})$ attached by flexible ducting (Hearn et al., 1975). At 2-4 weeks after group formation the social groups were maintained in home cages.

Within 2-3 days of forming the groups a dominance hierarchy was established (Abbott \& Hearn, 1978) which amongst the females consisted of a dominant (rank 1) female and her subordinates (ranks 2 and below). The ranking order was confirmed using behavioural analysis of recorded aggressive and submissive interactions between group members. Briefly, the highest ranking female received most submissions and the least aggression and the lowest ranking female received most aggression and the least submissions (Abbott, 1984; Abbott \& Hearn, 1978). Interactions involving food and water were excluded from the analysis. The rank order within a group strictly defined reproductive prowess; only the dominant female was capable of ovulating. The standardized social groups therefore contained 1-3 reproductively suppressed subordinate females. Removal of the subordinate females from the group and the constraints of the social hierarchy led to the commencement of ovarian cyclicity in these females (Abbott \& Hearn, 1978; Abbott et al., 1988).

\section{Blood sampling and assessment of ovarian function}

Blood samples $(0.3 \mathrm{ml})$ were collected from the femoral vein every $\mathrm{l}-3$ days between $09: 00 \mathrm{~h}$ and 13:00 $\mathrm{h}$ (Hearn. 1977) within $5 \mathrm{~min}$ of the animal being removed from its cage. The animals remained unanaesthetized throughout the procedure and were rewarded with a small fruit juice drink. Blood was collected into heparinized syringes and processed as described by Abbott et al. (1981) before hormone assay. The frequency of blood sampling was sufficient to determine ovarian function through the measurement of plasma progesterone concentrations. Dominant female marmoset monkeys have a 28-day ovarian cycle inclusive of a luteal phase lasting approximately $19-20$ days during which plasma progesterone levels are $>10 \mathrm{ng} / \mathrm{ml}$ (Harlow et al., 1983). The day of ovulation was considered to be the day before plasma progesterone concentrations increased to $>10 \mathrm{ng} / \mathrm{ml}$ and remained above this level for approximately 19-20 days. Within this blood sampling regimen accuracy of the estimation of the day of ovulation was limited to plus or minus 1 day.

To prevent pregnancy, an i.m. injection of the prostaglandin F-2 $\alpha$ analogue cloprostenol (0.5 $\mu \mathrm{g})$ (Estrumate; ICI, Macclesfield, Cheshire, UK; Summers et al., 1985) was given 14-20 days after ovulation. This prompted luteolysis and a return to the follicular phase (plasma progesterone $<10 \mathrm{ng} / \mathrm{ml}$ ) for approximately $8-10$ days. 


\section{Progesterone enzymeimmunoassay}

Progesterone concentrations were measured in 5- $\mu$ l portions of unextracted plasma using an enzyme-linked immunoabsorbent technique (Hodges et al., 1988) modified from a heterologous enzyme immunoassay described by Sauer $e t$ al. (1986). An anti-progesterone antiserum was raised in sheep and used to coat each well of a microtitre plate. Progesterone $(1 \mu \mathrm{g} / \mathrm{ml})$ dissolved in toluene was dried under nitrogen, reconstituted in PAS-gelatin buffer containing charcoal-treated marmoset plasma $(1: 15 \mathrm{v} / \mathrm{v})$ and serially diluted to produce a range of standards $(1.5-$ $200 \mathrm{pg} /$ well). Unextracted plasma samples and quality controls were diluted 1:30 with PAS-gelatin buffer containing charcoal-treated marmoset plasma (1:30 v/v). To each $100 \mu \mathrm{l}$ of standard and sample, $400 \mu \mathrm{l}$ conjugate $(1: 16000)$ were added and, from this, duplicate $200 \mu \mathrm{l}$ samples were placed in the wells of the plate which was then sealed. After an initial $2 \frac{1}{2} \mathrm{~h}$ incubation in a humid chamber at room temperature, each well was rinsed with PAS gelatin buffer and $200 \mu \mathrm{l}$ substrate ( $p$-nitrophenylphosphate dissolved in diethanolamine buffer) were added. The plates were resealed and incubated in a humid chamber for $1 \mathrm{~h}$ at $37^{\circ} \mathrm{C}$. Subsequently, $50 \mu 13 \mathrm{~N}-\mathrm{NaOH}$ were added to stop the reaction and the optical density of each well was measured at $405 \mathrm{~nm}$ in an automatic plate reader. The standard curve was plotted as percentage bound against known concentrations of standard. A substrate-only well acted as a blank.

The sensitivity of the assay (determined as $90 \%$ binding) was $1.6 \mathrm{ng} / \mathrm{ml}$ progesterone. The inter-and intra-assay coefficients of variation were $14.3 \%$ and $11.6 \%$, respectively, as determined using high $(49.2 \pm 0.7 \mathrm{ng} / \mathrm{ml}$, mean \pm s.e.m., $\mathrm{N}=20)$ and low $(10 \cdot 7 \pm 0 \cdot 3 \mathrm{ng} / \mathrm{ml}, \mathrm{N}=20)$ pools of marmoset plasma.

\section{LH bioassay}

LH was measured in unextracted plasma samples using an in-vitro bioassay system utilizing testosterone production by mouse Leydig cells (Harlow et al., 1984; Hodges et al., 1987; Abbott et al., 1988). Plasma samples (16 $\mu$ ) were assayed in duplicate at 1:50 and 1:100 dilutions. The LH standard used was the 2nd International Reference Preparation of human pituitary gonadotrophin (78/549); triplicate samples were taken over the range 6.25-200 i.u./l. Standards and samples were incubated with a preparation of Leydig cells $\left(1 \times 10^{5}\right.$ cells/tube $)$ for $3 \mathrm{~h}$ at $34^{\circ} \mathrm{C}$ in a $95 \%$ $\mathrm{O}_{2}: 5 \% \mathrm{CO}_{2}$ atmosphere. The Leydig cells were obtained from 5-7-week-old mice (formerly Tucks No. 1 strain; outbred at the Institute of Zoology).

Testosterone production was measured by radioimmunoassay using ${ }^{125}$ I-labelled testosterone-3carboxymethyloxime histamine (sp. act. $1.7 \times 10^{3} \mathrm{Ci} / \mathrm{mmol}$ : MRC Reproductive Biology Unit, Edinburgh, Webb ('t al., 1985) and an antiserum raised in sheep against the testosterone-3-carboxymethyloxime. The maximum crossreactivity of the antiserum observed with other steroids was $12 \cdot 1 \%$ with dihydrotestosterone, $3 \cdot 3 \%$ with androsterone and $<1 \%$ with other steroids (Webb et al., 1985). Inter- and intra-assay coefficients of variation were $6.2 \%$ and $11.9 \%$ respectively, as determined from marmoset plasma pools $(27.5 \pm 0.4$ i.u. $/ 1, \mathrm{~N}=15$, and $123.2 \pm 4.3$ i.u. $/$, $N=15)$.

\section{Experimental protocol}

Control group 1. Eight subordinate female marmoset monkeys housed with their social groups were removed and housed alone in a clean cage $(\mathrm{N}=7)$ or were placed in a new group where they became dominant $(\mathrm{N}=1)$.

Control group 2. Five subordinate female marmosets were removed from their social groups and housed separately in clean cages. Thrice daily a cotton-bud, moistened with saline was wiped over the external nares and upper palate of the subordinate females. Swabs from the circumgenital region of other subordinate females or males from the group were not used as control procedures because of likely contamination from dominant females. The subordinate females were then immediately returned to their own cages. This control phase lasted 6-8 weeks whereupon the isolated subordinate females were returned to their original social groups for 3-5 weeks before commencing the scent transfer phase.

\section{Scent transfer protocol}

Eight subordinate female marmoset monkeys ( 5 of which had previously undergone the control group 2 phase: see above) were removed from their social groups and housed in half of the cage of the original group. The cage was divided by a solid partition preventing visual and tactile access between the isolated subordinate female and her social group. Thrice daily for 49 days the circumgenital area of the dominant female was wiped with a cotton-bud moistened with saline. The cotton-bud was then wiped over the external nares and upper palate (the openings to the main and accessory olfactory epithelium) of the subordinate female that had been isolated from the same social group. Following this the cages of the dominant female and her isolated subordinate female were interchanged, i.e. the isolated subordinate female was put into the cage the dominant female and her other subordinate females had just vacated, and the dominant female and her other subordinate females went into the cage in which the isolated subordinate female had previously been housed. When scent transfer was initiated, in 7 of 8 groups the males were removed from the groups and the dominant females $(N=8)$ were housed singly $(N=3)$, with a subordinate female $(N=4)$, or with an intact male $(\mathrm{N}=1)$. 


\section{Statistical analysis}

One-way analysis of variance for repeated measures (ANOVA, using SAS; Helwig \& Council, 1979) was used to compare the times to onset of ovulation amongst the following three phases: (i) control group 1; (ii) control group 2; and (iii) scent transfer. Regression analysis was performed to compare the time spent as a subordinate in a group to the time taken to ovulate after removal from the group, for each of the aforementioned phases. The time spent as a subordinate female in a group was submitted to log transformation to reduce skew in the data (Helwig \& Council, 1979; Sokal \& Rohlf, 1981).

ANOVA was used to compare the plasma concentrations of $\mathrm{LH}$ across the four phases of the experiment, whilst: (1) subordinate females were maintained with their dominant female and group $(\mathrm{N}=8)$; (2) subordinate females were housed singly and underwent control group 2 procedure, i.e. no scent contact with their dominant females $(\mathrm{N}=5)$; (3) subordinate females were returned to their dominant female and group $(N=5)$; and (4) subordinate females were housed singly but were maintained in scent contact with their dominant females $(\mathbf{N}=8)$. Before analysis by ANOVA, the $\mathrm{LH}$ values were $\log _{10}$ transformed, a standard method for reducing heterogeneity of variance and increasing the linearity of the data (Helwig \& Council, 1979; Sokal \& Rohlf, 1981). Duncan's multiple range test was then performed to compare the transformed means of each group.

\section{Results}

\section{Control groups 1 and 2}

All subordinate females that were isolated from their social groups and maintained without scent contact with their dominant females, in either control groups 1 or 2 ovulated within 2 weeks (see Table 1). Figure 1 shows the hormonal profiles of 2 subordinate females (Nos $388 \mathrm{~W}$ and $401 \mathrm{~W}$ ) typical of the subordinates that underwent the control group 2 study. When the subordinate females were maintained with their dominant females, the subordinates had low, acyclic circulating concentrations of $\mathrm{LH}$ and progesterone. Once removed from their dominant female and group on the control phase, Female $388 \mathrm{~W}$ ovulated on the 9 th day and Female $401 \mathrm{~W}$ ovulated on the 11 th day. The frequency of blood sampling (1-3 days) precluded observation of the LH peak before the first ovulation of Female 388W.

Table 1. Mean \pm s.e.m. days to onset of ovulation in subordinate female marmoset monkeys removed from their dominant females

\begin{tabular}{lcc}
\hline & $\begin{array}{c}\text { No. of } \\
\text { females }\end{array}$ & $\begin{array}{c}\text { Days to } \\
\text { onset of } \\
\text { ovulation }\end{array}$ \\
\hline $\begin{array}{l}\text { Control group 1 } \\
\text { (isolated or became } \\
\text { dominant in new group) }\end{array}$ & 8 & $10 \cdot 8 \pm 1 \cdot 4$ \\
$\begin{array}{l}\text { Control group 2 } \\
\text { Scent transfer phase }\end{array}$ & 5 & $10 \cdot 4 \pm 0.8$ \\
\hline
\end{tabular}

${ }^{*} P<0 \cdot 05$, compared with control group 1 or 2 (Duncan's multiple range test after ANOVA).

After their initial ovulation during the control group 2 phase, all 5 subordinate females exhibited luteal concentrations of plasma progesterone for at least 19-20 days indicative of the luteal phase of an ovulatory cycle. Of the 5 subordinate females, 2 (No. 388W, Fig. 1; No. 438W, data not shown) had a second ovulation. However, no further ovulations in the other 3 females (No. 401W, Fig. I(ii); No. 45IW; No. 402W) were apparent because plasma progesterone concentrations remained $>10 \mathrm{ng} / \mathrm{ml}$ after the initial ovulation throughout the rest of the control phase (4-6 weeks). 
(I/n*!) Hา $0-\bigcirc$
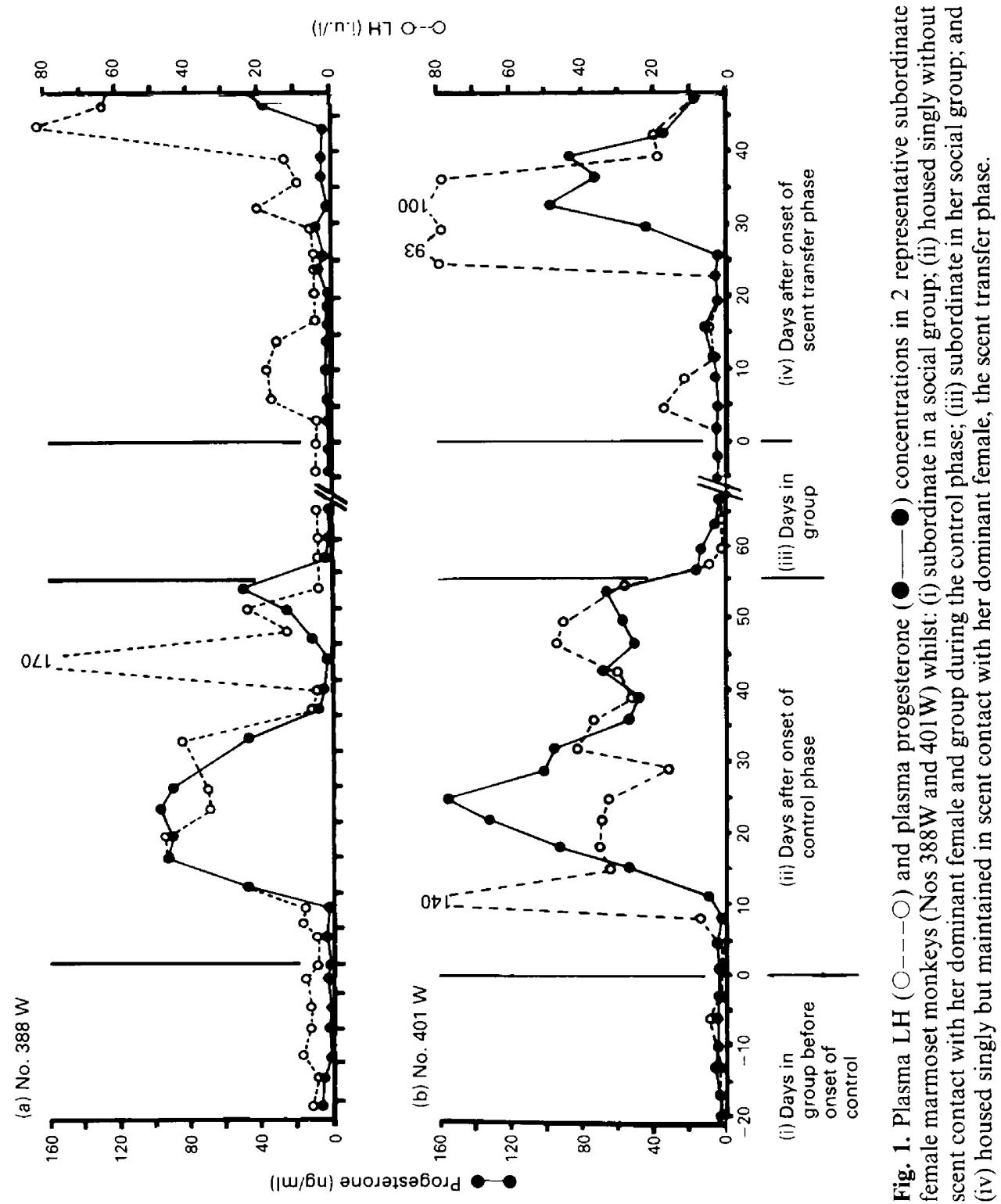
At the end of the control group 2 phase the subordinate females were re-housed with their dominant females, whereupon they resumed subordinate status. Plasma LH and progesterone concentrations in subordinates fell to $<2 \mathrm{i} . \mathrm{u} . / 1$ and $<10 \mathrm{ng} / \mathrm{ml}$, respectively, in less than 1 week and remained low and acyclic. All 5 subordinate females that underwent the control group 2 phase were returned to their dominant females for at least 3 weeks before the start of the scent transfer phase.

\section{Scent transfer phase}

When subordinate female marmosets were isolated from their dominant females but maintained in scent contact, there was a significant (ANOVA $\mathrm{F}(2,18)=7 \cdot 7, P<0.004$ ) delay in the onset of ovulation of $\sim 20$ days compared with control groups 1 or 2 (see Table 1). This is exemplified in Fig. 1 by Females $388 \mathrm{~W}$ and $401 \mathrm{~W}$ which, when returned to their dominant females and groups after the control group 2 phase, had low and acyclic levels of plasma LH and progesterone. These low levels of plasma $\mathrm{LH}$ and progesterone were maintained during the scent transfer phase until the females ovulated on Days 45 and 26 respectively.

Concentrations of plasma LH (mean \pm s.e.m.) during the scent transfer phase $(15.9 \pm 1.8$ i.u./l) were comparable to the low, acyclic values of subordinate females housed with their dominant female before or after the control phase $(3.7 \pm 0.4 \mathrm{i}$.u. $/ 1$ and $5.2 \pm 1.4 \mathrm{i} . \mathrm{u} . / 1$, respectively). However, the low concentrations of plasma LH seen throughout the scent transfer phase contrasted markedly $(P<0.05)$ with the higher values of plasma LH seen during the control phase $(35.5 \pm 4.4$ i.u. $/ 1)$.

Of the 8 subordinate females that underwent the scent transfer phase, 2 (Nos $373 \mathrm{~W}$ and 334W) did not ovulate throughout the entire 49-day period. When the time taken to ovulate during both control phases and the scent transfer phase was compared, regression analysis strongly suggested that, whilst the time spent as a subordinate in a group before removal had no influence upon the onset of ovulation in either control group $(\mathrm{R}=0 \cdot 14, \mathrm{~F}(1,4), P<0 \cdot 7$, and $\mathrm{R}=0 \cdot 35, \mathrm{~F}(1,3)$, $P>0 \cdot 5)$, it might have influenced the timing of onset of ovulation during the scent transfer phase ( $\mathrm{R}=0.66, \mathrm{~F}(1,6), P<0.07)$.

\section{Discussion}

These results clearly demonstrate that olfactory cues from dominant female marmosets play an important role in maintaining the suppression of ovulation in subordinate females. They are similar to those found in the closely related tamarin species, Saguinus fuscicollis and S. oedipus, which had also suggested a role for scent of breeding females in maintaining acyclicity (Epple \& Katz, 1984) and delaying ovulation (Savage et al., 1988) in subordinate daughters living within their natal group.

However, neither in the marmoset monkey nor in the tamarin species are pheromonal cues alone capable of maintaining complete suppression of ovulation. Most singly-housed subordinate female marmoset monkeys maintained in scent contact with their dominant female ovulated at some point although the onset of ovulation was delayed compared to control females. Similarly, removal of daughter tamarins from groups and pairing with a male resulted in either increased, but not cyclical, levels of urinary oestrogen (Epple \& Katz, 1984) or a delay in the onset of ovulation compared to controls (Savage et al., 1988).

Of the 5 subordinate female marmoset monkeys that underwent the control phase of the experiment, 3 did not undergo a second ovulation within the 6-8 week timespan. Rather they appeared to have a prolonged luteal phase from their first ovulation. There is variation of ovarian cycle lengths in the marmoset monkey: Harding et al. (1982) suggested that the luteal phase could last 17-72 days. Therefore it appears unlikely that the lengthened luteal phases were a result of control procedures per se. It is unlikely that the progesterone measured was of adrenal origin because ovariectomized females have low plasma progesterone concentrations (Harding et al., 1982; Kendrick \& Dixson, 1984).

As fresh scent was introduced to the separated subordinate female marmosets thrice daily, the longevity of the pheromonal signal itself was not an issue in this experiment. Rather, regression 
analysis of the timing of ovulation during the scent transfer phase suggested that the length of exposure of the subordinate female to her dominant female might have influenced the timing of onset of ovulation. This implies an influence of conditioning to the dominant's odour upon the timing of ovulation in subordinate females maintained in scent contact only with their dominant females. Any response of conditioning to the dominant female's odour was not investigated here because, as in previous studies of scent transfer in female callitrichids (Epple \& Katz, 1984; Savage et al., 1988), the scent transferred to the isolated female marmosets was from their own dominant female. Whether scent from another dominant female would have been equally effective is a matter for future research. In other species, studying the effect of pheromones on reproductive activity has, in some cases, suggested a synergistic effect of non-pheromonal cues, such as tactile (onset of puberty in female mice: Bronson \& Maruniak, 1975) and visual and behavioural (onset of ovulation in sheep: Cohen-Tannoudji et al., 1986) cues. Whilst it is uncertain whether other cues, e.g. visual or tactile, play a role in the suppression of subordinate female marmoset monkeys, auditory cues played no apparent role as separated females from both control and scent transfer groups were able to maintain auditory contact with their dominant females.

Having discovered a role for pheromone-like cues in maintaining the suppression of reproductive activity in subordinate female marmosets, it is important to determine whether selective lesioning of either main or accessory olfactory pathways is sufficient to reverse the acyclic state of group-housed subordinate females, and thereby which olfactory route the inhibitory cue is mediated. It is also of importance to ascertain the chemical composition of this putative pheromone to enable an artificial inhibiting cue to be manufactured and its efficacy established.

We thank Dr A. P. F. Flint and Dr H. M. Moore for criticism of the manuscript; M. J. Llovet, M. Bullock, J. Rozowski and J. Geddes for care and maintenance of the animals and assistance throughout the project; T. J. Dennett and M. J. Walton for preparation of the figure; and M. B. Foreman and R. Gray for typing the manuscript. This work was supported by a grant from the Wellcome Trust.

\section{References}

Abbott, D.H. (1984) Behavioural and physiological suppression of fertility in subordinate marmoset monkeys. Am. J. Primatol. 6, 169-186.

Abbott, D.H. (1987) Behaviourally mediated suppression of reproduction in primates. J. Zool., Lond. 213, $455-470$.

Abbott, D.H. (1989) Social suppression of reproduction in primates. In Comparative Socioecology. The Behavioural Ecology of Humans and Other Mammals, pp. 285-304. Eds V. Standen \& R. A. Foley. Blackwell Scientific Publishers, Oxford.

Abbott, D.H. \& Hearn, J.P. (1978) Physical, hormonal and behavioural aspects of sexual development in the marmoset monkey, Callithrix jacchus. J. Reprod. Fert. 53, 155-166.

Abbott, D.H., McNeilly, A.S., Lunn, S.F., Hulme, M.J. \& Burden, F.J. (1981) Inhibition of ovarian function in subordinate female marmoset monkeys (Callithrix jacchus jacchus). J. Reprod. Fert. 63, 335-345.

Abbott, D.H., Hodges, J.K. \& George, L.M. (1988) Social status controls LH secretion and ovulation in female marmoset monkeys (Callithrix jacchus). J. Endocr. 117, 329-339.

Bronson, F.H. \& Maruniak, J.A. (1975) Male-induced puberty in female mice: evidence for a synergistic action of social cues. Biol. Reprod. 13, 94-98.
Cohen-Tannoudji, J., Locatelli, A. \& Signoret, J.P. (1986) Non-pheromonal stimulation by the male of $\mathrm{LH}$ release in the anoestrous ewe. Physiology and Behaviour 36, 921-924.

Epple, G. \& Katz, Y. (1984) Social influences on estrogen excretion of ovarian cyclicity in Saddle-back tamarins (Saguinus fuscicollis). Am. J. Primatol. 6, 215-227.

French, J.A., Abbott, D.H. \& Snowdon, C.T. (1984) The effect of social environment on estrogen excretion, scent marking and sociosexual behaviour in Tamarins (Saguinus oedipus). Am. J. Primatol. 6, 155-167.

Harding, R.D., Hulme, M.J., Lunn, S.F., Henderson, C. \& Aitken, R.J. (1982) Plasma progesterone levels throughout the ovarian cycle of the common marmoset (Callithrix jacchus). J. med. Primatol. 11, 43-51.

Harlow, C.R., Gems, S., Hodges, J.K. \& Hearn, J.P. (1983) The relationship between plasma progesterone and the timing of ovulation and early embryonic development in the marmoset monkey (Callithrix jacchus). J. Zool., Lond. 201, 273-282.

Harlow, C.R., Hearn, J.P. \& Hodges, J.K. (1984) Ovulation in the marmoset monkey: endocrinology, prediction and detection. J. Endocr. 103, 17-24.

Downloaded from Bioscientifica.com at 04/26/2023 10:41:58AM via free access 
Hearn, J.P. (1977) The endocrinology of reproduction in the common marmoset, Callithrix jacchus. In The Biology and Conservation of the Callitrichidae, pp. 163-171. Ed. D. G. Kleiman. Smithsonian Institution, Washington, D.C.

Hearn, J.P. (1983) The common marmoset (Callithrix jacchus). In Reproduction in New' World Primates, pp. 181-215. Ed. J. P. Hearn. M.T.P. Press Ltd, Lancaster.

Hearn, J.P., Lunn, S.F., Burden, F.J. \& Pilcher, M.M. (1975) Management of marmosets for biomedical research. Lab. Anim. 9, 125-134.

Helwig, J.T. \& Council, K.A. (1979) SAS User's Guide. SAS Institute Inc., Cary.

Hodges, J.K., Cottingham, P.G., Summers, P.M. \& Yingnan, L. (1987) Controlled ovulation in the marmoset monkey (Callithrix jacchus) with human chorionic gonadotrophin following prostaglandininduced luteal regression. Fert. Steril. 48, 299-305.

Hodges, J.K., Green, D.I., Cottingham, P.G., Sauer, M.J., Edwards, C. \& Lightman, S.L. (1988) Induction of luteal regression in the marmoset monkey (Callithrix jacchus) by a gonadotrophin-releasing hormone antagonist and the effects on subsequent follicular development. J. Reprod. Fert. 82, 743-752.

Hubrecht, R.C. (1984) Field observations on group size and composition of the common marmoset (Callithrix jacchus jacchus), at Tapacura, Brazil. Primates 25, 13-21.

Kendrick, K.M. \& Dixson, A.F. (1984) Ovariectomy does not abolish proceptive behaviour cyclicity in the common marmoset (Callithrix jacchus). J. Endocr. 101, 155-162.

Ruiz de Elvira, M.-C. \& Abbott, D.H. (1986) A backpack system for long-term osmotic infusions into unrestrained marmoset monkeys. Lab. Anim. 20, $329-334$.

Sauer, M.J., Foulkes, J.A., Worsfold, A. \& Morris, B.A. (1986) Use of progesterone 11-glucuronide-alkaline phosphatase conjugate in a sensitive microtitre-plate enzymeimmunoassay of progesterone in milk and its application to pregnancy testing in dairy cattle. $J$. Reprod. Fert. 76, 375-391.

Savage, A., Ziegler, T.E. \& Snowdon, C.T. (1988) Sociosexual development, pair bond formation, and mechanisms of fertility suppression in female cotton-top tamarins (Saguinus oedipus oedipus). Am. J. Primatol. 14, 345-359.

Sokal, R.R. \& Rohlf, F.J. (1981) Biometry: The Principles and Practice in Biological Research, 2nd edn. W.H. Freeman \& Co., New York.

Stevenson, M.F. ( I978) The behaviour and ecology of the common marmoset (Callithrix jacchus jacchus) in its natural environment. In Biology and Behaviour of Marmosets, p. 298. Eds H. Rothe, H. J. Wolters \& J. P. Hearn. Eigenverlag Hartmut Rothe, Göttingen.

Stevenson, M.F. \& Poole, T.B. (1976) An ethogram of the Common marmoset (Callithrix jacchus jacchus): general behavioural repertoire. Anim. Behav. 24, 428-451.

Stevenson, M.F. \& Rylands, A.B. (1988) The marmosets, genus Callithrix. In Ecology and Behaviour of Neotropical Primates, pp. 131-222. Eds R. A. Mittermeier, A.D. Rylands, A. Coimbra-Filho \& G. A. B. Fonseca. World Wildlife Fund, Washington, DC.

Summers, P.M., Wennick, C.J. \& Hodges, J.K. (1985) Cloprostenol-induced luteolysis in marmoset monkeys (Callithrix jacchus). J. Reprod. Fert. 73, 133-138.

Sutcliffe, A.G. \& Poole, T.B. (1978) Scent marking and associated behaviour in captive common marmosets (Callithrix jacchus jacchus) with a full description of the histology of scent glands. J. Zool., Lond. 185, 41-56.

Webb, R., Baxter, G., McBride, D., Nordblom, G.D. \& Shaw, M.P.K. (1985). The measurement of testosterone and oestradiol-17 $\beta$ using iodinated tracers and incorporating an affinity chromatography extraction procedure. J. Steroid Biochem. 23, 1043-1051.

Received 5 January 1990 